\title{
Institutional effects on nurses' working conditions: a multi-group comparison of public and private non-profit and for-profit healthcare employers in Switzerland
}

Remo Aeschbacher ${ }^{1 *}$ (D) and Véronique Addor ${ }^{2}$

\begin{abstract}
Background: In response to the need for competitive recruitment of nurses resulting from the worldwide nursing shortage, employers need to attract and retain nurses by promoting their competitive strengths in their working conditions (WCS) and by addressing their competitive weaknesses. This study investigated workplace differences between public hospitals (PuHs), private for-profit hospitals (PrHs), socio-medical institutions (SOMEDs), home care services (HCs), private medical offices (PrOs) and non-profit organisations (NPOs), helping to provide a foundation for competition-oriented institutional employer branding and to increase transparency in the labour market for nurses.
\end{abstract}

Methods: Data from the Swiss Nurses at Work study of the career paths of 11232 nurses who worked in Switzerland between 1970 and 2014 were subjected to secondary analysis, assessing the effect of institutional characteristics on self-reported determinants of job satisfaction (such as WCS) using multivariate linear regression and post hoc tests with Bonferroni-adjusted significance levels. Principal component analysis was used to reduce the number of WCS in the original study.

Results: Nurses at PuHs and PrHs were less likely to experience autonomy, flexibility of work hours and participation in decision-making than those at other workplaces. Although PuHs were rated higher than PrHs in terms of satisfaction with salary and advancement opportunities, they were associated with more alienating work factors, such as stress and aggression. SOMED workplaces were significantly more often associated with alienating conditions and low job satisfaction, but were rated higher than the other institutions in terms of participation in decision-making. The nurses' ratings implied that PrO workplaces were more likely to offer a mild work environment, social support and recognition than other institutions, but that advancement opportunities were limited. NPO workplaces were associated with the highest degree of autonomy, flexibility, participation, recognition, organisational commitment and job satisfaction. In these respects, HC and NPO workplaces received similar ratings, although the HC workplaces were associated with a significantly lower organisational commitment and significantly lower job satisfaction.

Conclusions: Due to their structural characteristics, NPOs, SOMEDs and HCs can attract nurses seeking greater self-determination, PuHs can attract career-oriented nurses, and PrOs and PrHs are likely to attract nurses through offering less-stressful working conditions.

Keywords: Comparative study, Hospitals, Non-profit organisations, Nursing, Nurse, Home care, Types of institutions, Working conditions

\footnotetext{
* Correspondence: remo.aeschbacher@gmx.ch

${ }^{1}$ University of Fribourg (CH), Bd de Pérolles 90, CH-1700 Freiburg, Switzerland

Full list of author information is available at the end of the article
}

(c) The Author(s). 2018 Open Access This article is distributed under the terms of the Creative Commons Attribution 4.0 International License (http://creativecommons.org/licenses/by/4.0/), which permits unrestricted use, distribution, and

reproduction in any medium, provided you give appropriate credit to the original author(s) and the source, provide a link to the Creative Commons license, and indicate if changes were made. The Creative Commons Public Domain Dedication waiver (http://creativecommons.org/publicdomain/zero/1.0/) applies to the data made available in this article, unless otherwise stated. 


\section{Background}

\section{Study aims}

Unlike other skilled professions, where staff shortages tend to be short-lived, the worldwide shortage of nurses has persisted. The reasons are diverse, but major factors include generational imbalances and training capacity problems which prevent the supply of labour catching up with the increased demand [1,2]. Retention of nurses is the most efficient measure to reduce the shortage [3], but a high turnover in the healthcare workforce is a problem worldwide. Work and nature of the work environment, which vary across institutional settings, are key factors, so working conditions (WCS) of nurses have received much research attention [4-7].

However, these have often focussed on factors that affect the nursing workforce as a whole; few have compared WCS between different institutional settings to facilitate type-specific human resource management. The present study therefore focuses, from a management perspective, on how WCS varied across types of healthcare institutions in Switzerland. Switzerland has a highly developed healthcare system shaped by federalist policies, direct democracy and a managed competitive environment. The system ensures direct and immediate access to care, funded via mandatory health insurance. Life expectancy in Switzerland is among the highest in Europe and care quality is generally viewed to be good or very good [8].

The aims of this study were to identify the competitive strengths and weaknesses of specific types of organisations with regard to nurses' WCS and to explore the potential for improved setting-specific human resource management. The study addressed these aims through an explorative secondary analysis of the extensive experience captured by the comprehensive Swiss Nurses at Work study. This included six main types of nurses' employers. By distinguishing these, the present study overcomes the traditional approach of two- or three-group comparisons, contributing to a foundation for sharper, organisation-specific institutional employer branding.

\section{Literature review}

Studies of WCS in nursing have compared various sizes of organisations (e.g. hospitals vs. outpatient care), types of treatment (e.g. critical care vs. medical-surgical care vs. step-down units and challenging vs. non-challenging patients) and ownership types (private for-profit vs. private non-profit vs. public institutions). These will be considered in turn.

Compared with those working in smaller settings, nurses in larger organisations experience more work strain and burnout [9-14], as well as reporting greater burden [15], less autonomy and participation and more regulation $[11,16]$. Communication is less favourable and nurses are less likely to perceive that patients are provided with appropriate psychosocial care and more likely to perceive that patients are discharged too early [15]. Nurses at larger institutions are more likely to report their work as less meaningful [17] and to have less organisational commitment [11] and higher job dissatisfaction and greater intention to leave [14, 18-20]. Nurse turnover is higher in larger units [21].

Geriatric care and caring for patients who display aggressive, disruptive or responsive behaviour are associated with greater work strain, burnout and dissatisfaction, less support between colleagues and increased intention to leave [10, 16, 22-27]. Conversely, nurses in geriatric care showed higher professional identification and organisational commitment [11].

Compared with those working in stationary treatment and outpatient care, nurses in home care experience less work strain, burnout and job dissatisfaction [11, 13, 23], less regulation and greater independence [11, 17]; they also have more focussed and rewarding patient relationships [11] and potentially a better team climate [28] and they are more likely to consider their work meaningful $[17,29]$. Nurses in home care, outpatient and day-care services are less likely to quit than nurses in stationary treatment [19-21]. Nurses working in paediatric and critical care units report more favourable working environments and higher job satisfaction than nurses working in medical-surgical and step-down units [30, 31].

Private sector nurses receive greater recognition than those in the public sector [16] and are more satisfied with their supervision, more committed to their work and have higher morale [32]. Nurses at private hospitals have a smaller administrative workload than those at public hospitals [15] and they experience less violence [33]; however, they are less satisfied with their salary [16] and private hospitals offer less good training and career opportunities [34]. Private sector nurses in low-income and middle-income countries experience less stress [35], higher employment benefits and greater recognition than those in the public sector [36], reporting less burnout, better care quality and higher job satisfaction [37-39]. In these countries, private organisations tend to provide poorer patient outcomes than public organisations, but offer greater timeliness and hospitality to patients [40].

Nurses in for-profit organisations are faced with lower staffing levels [41], report higher burnout levels [42] and have lower wages [43]. For-profit organisations provide lower care quality [44-46] and, generally, their staff perceive less job autonomy and report lower job satisfaction [47, 48]. Working in non-profit hospitals is associated with a higher degree of organisational commitment than working in public and private for-profit hospitals [49]. 


\section{Theoretical perspective on institutional differences}

The most relevant variables for differentiating healthcare institutions are organisational size, activity type and ownership and goal systems $[50,51]$. These can, therefore, be considered the major mediators of potential differences in WCS between healthcare institutions.

Although the impact of these mediators on WCS was not tested directly in this study, they were used as a basis for generating seven broad hypotheses regarding institutional differences (Table 1), derived from multitheoretical arguments (see Additional file 1 for a more thorough review) and previous research. These hypotheses were then tested statistically.

\section{Methods}

Data

We tested our hypotheses regarding the institutional differences using data from the Swiss Nurses at Work study [52]. This was the first retrospective longitudinal cohort study of the entire career paths of nurses who worked in Switzerland between 1970 and 2014. Data from 15301 nurses were collected between September 2014 and February 2015 through an online validated questionnaire in the three main languages spoken in Switzerland; this was developed by the research team using some items from existing instruments. The survey assessed various aspects of workplace quality and WCS and included a parallel section on simultaneous personal events, socio-demographic data and personality types, allowing a deeper analysis of possible determinants of nurses quitting their job.

\section{Institutional categories}

We defined six main types of organisations as independent variables (Table 2): public hospitals ( $\mathrm{PuHs}$ ), private for-profit hospitals (PrHs), private medical offices (PrOs; this includes general practitioners), socio-medical institutions (SOMEDs) such as nursing homes, non-profit organisations (NPOs; i.e., associations, foundations and international organisations) and home care services (HCs). ${ }^{1}$ Together, these employ about $90 \%$ of all nurses in Switzerland.

\section{Sample}

Of the initial 15301 participants of the Nurses at Work study, 12755 reported experiences for at least one episode of work as a nurse. From these 17560 work episodes, 1265 were excluded because the employment was for less than 1 month or job tenure information was missing and 236 because the individuals worked less than one full day per week or workload information was missing. Finally, we excluded 1756 episodes at healthcare institutions not belonging to one of the six organisation types introduced earlier, including self-employment. The resulting sample captured 14303 work episodes from 11 232 nurses (Additional file 2). However, when sex and age were included in the regression models, the sample size decreased substantially because of many missing values for these variables. We, therefore, analysed a subsample of the cases with complete information for all control variables, which included 8399 work episodes from 6490 nurses (Table 3). The following sections refer only to the results of the analyses of the fully adjusted models (i.e. based on the subsample). Results for the analyses of the extended sample are presented in Additional files 3 and 4 .

\section{Measures of WCS}

The participants were asked to rate their experiences of their current workplace and one previous workplace. All items were assessed with 4-point or 5-point Likert scales according to the original validated instrument, with the option to reply do not know/not applicable. To allow comparison of the means and effects, the answers for items measured on a 5-point scale were rescaled to a 4-point scale ranging from 1 (e.g. very unsatisfying) to 4 (e.g. very satisfying). ${ }^{2}$ In the analyses, we regarded these as quasi-interval scales. Multi-item variables were constructed by averaging the scores of the items. The reliability and validity of most items in the Nurses at Work survey were supported by previous studies, although, in some cases, pre-tested items with wording tailored to the nursing context were used.

Principal component analysis was used to reduce the number of variables of the original study (described in Statistical analysis, below). Ultimately, 12 variables were used in the analyses: autonomy, participation, flexibility of work hours, relationships, recognition, alienation, advancement, organisational commitment, professional identification, job satisfaction, satisfaction with salary and turnover intention. ${ }^{3}$

Autonomy (related to self-determination) was measured by an item proposed by Spreitzer's Psychological Empowerment Scale [53]; participation was measured by three items $(\alpha=.78)$ based on the Practice Environment Scale of the Work Index Revised (PES-NWI) [54]; and flexibility of work hours was measured using three pre-tested items $(\alpha=.67)$ addressing the degree of consideration of personal requests regarding shifts, workload and department. The relationships scale comprised five variables $(\alpha=.80)$ : a formative measure of the quality of internal communication, assessed by three items (specific to Nurses at Work) that measured communication with superiors, physicians and colleagues; a four-item measure of social support from the nurse's superiors $(\alpha=.92)$; a two-item measure of support from colleagues $(\alpha=.62)$, both based on the Job Content Questionnaire [55]; an inverted variable that measured 


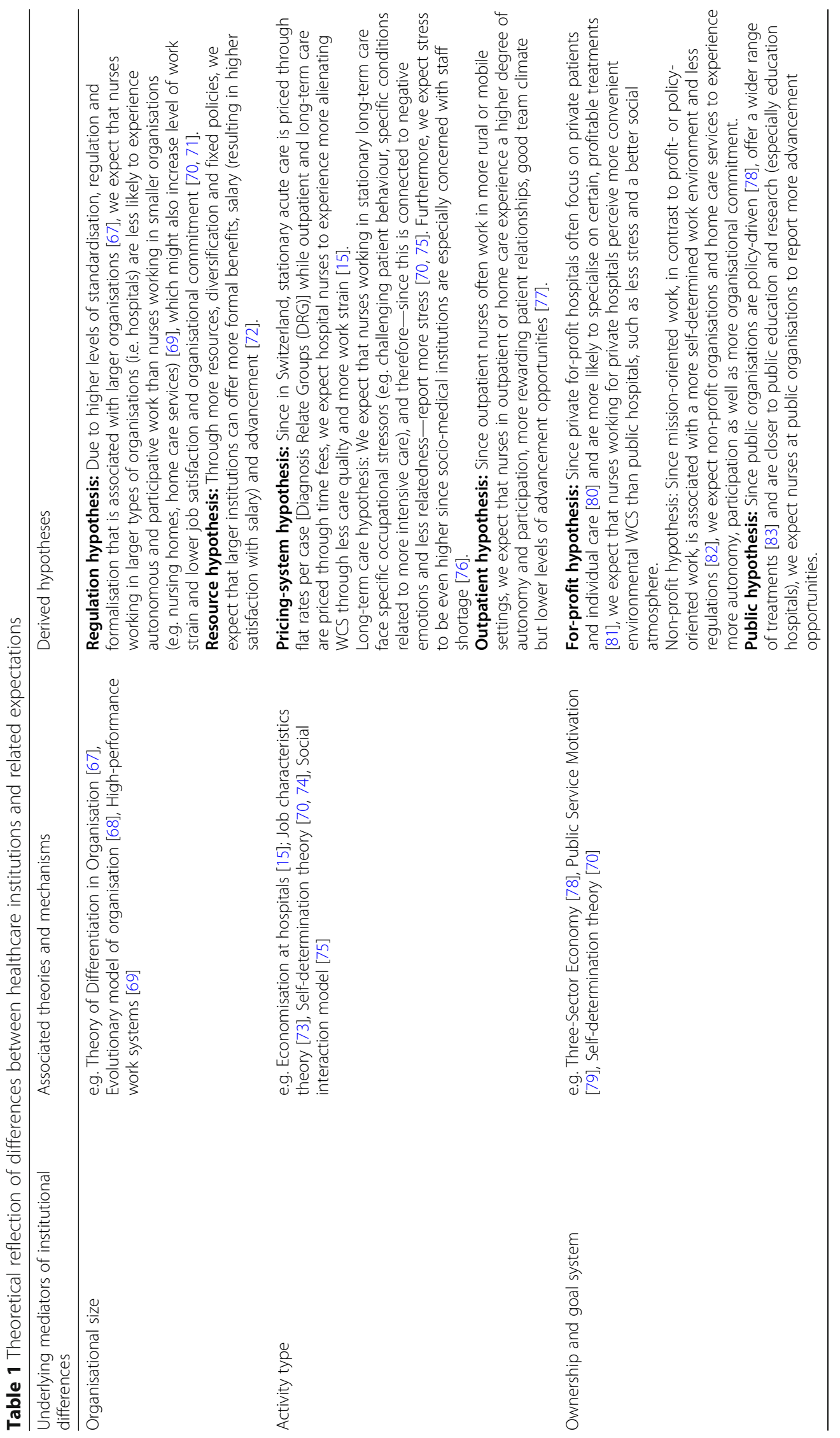


Table 2 Six types of healthcare institutions in Switzerland and their organisational characteristics

\begin{tabular}{|c|c|c|c|}
\hline Type of institution & Activity type & Organisational size & Ownership and goal system \\
\hline Public hospitals (PuHs) & Acute, stationary medical care & Large & $\begin{array}{l}\text { Public; oriented towards public policy } \\
\text { (policy-oriented) }\end{array}$ \\
\hline Private hospitals (PrHs) & Acute, stationary medical care & Medium to large & Private; profit-oriented \\
\hline Private medical offices (PrOs) & Outpatient medical care & Small & Private; profit-oriented \\
\hline Socio-medical institutions (SOMEDs) & $\begin{array}{l}\text { Residential care, long-term care } \\
\text { or day-care }\end{array}$ & Medium & $\begin{array}{l}\text { Private, public or hybrid; policy-oriented, } \\
\text { mission-oriented or hybrid }\end{array}$ \\
\hline Non-profit organisations (NPOs) & Miscellaneous & Small to large & Private; mission-oriented \\
\hline Home care services (HCs) & Home care, long-term care & Small & $\begin{array}{l}\text { Private, public; profit-oriented or mission- } \\
\text { oriented }\end{array}$ \\
\hline
\end{tabular}

harassment by colleagues or supervisors with four items $(\alpha=.72)$ based on the Negative Acts Questionnaire Short Version [56]; and a single-item measure of the general work atmosphere (specific to Nurses at Work).

Recognition was assessed by four items $(\alpha=.71)$ based on the Copenhagen Psychosocial Questionnaire (COPSOQ-2) [57]. The alienation scale captured impediments that explicitly hindered work and aspects of negative work through five variables $(\alpha=.68)$ : work strain, measured with an item from the French version of COPSOQ [58]; impairment by non-nursing tasks, measured by an item from the Contraintes Psychosociales et Organisationnelles questionnaire [59]; two items $(\alpha=.79)$ based on the Ryden Aggression Scale [60], measuring physical and verbal aggression by patients and colleagues; three items $(\alpha=.79)$ measuring exhaustion, based on COPSOQ-2 [57] and the Maslach Burnout Inventory [61]; and an inverse nursing quality measure comprising two items $(\alpha=.68)$ from the PES-NWI. Advancement was measured by three items $(\alpha=.75)$ that assessed the opportunity to use skills and learn new things, and promotion opportunities, based on COPSOQ-2 and the job satisfaction scale [62]. Organisational commitment and professional identification were assessed with one and four items $(\alpha=.90)$, respectively, based on the work of Allen and Meyer [63]. Overall job satisfaction was assessed with one item based on the COPSOQ-2 and satisfaction with salary assessed satisfaction with salary compared to similar professions (specific to Nurses at Work). Turnover intention was assessed with a single-item measurement based on the Mobley, Horner and Hollingsworth Questionnaire [64].

\section{Statistical analysis}

Principal component analysis was applied to the constructs of the original study to reduce the number of variables and obtain orthogonal (independent) factors via varimax rotation. The Kaiser-Meyer-Olkin sampling adequacy measure indicated that the analysis was appropriate. ${ }^{3}$ Concepts or variables with either moderate loading on several components or insufficient loading on

Table 3 Description of the subsample analysed in the fully adjusted models

\begin{tabular}{lll}
\hline Sample of individuals captured in the analysis $(n=6490)$ & $n$ & Percent/years \\
Women & 5659 (male 831) & $87.2 \%$ (male 12.8\%) \\
Average age (ages ranging from 20 to 64 years) & & 42.0 years \\
Highest diploma & & $58.0 \%$ \\
Basic nurse diploma & 3765 & $18.1 \%$ \\
Specialisation diploma (postgraduate studies, certificate of advanced studies) & 1174 & $9.2 \%$ \\
Higher professional education (HöFa 1 \& 2, diploma of advanced studies) & 594 & $14.7 \%$ \\
Bachelor, Master or PhD in nursing or other discipline & 957 & Percent \\
Sample of reported work episodes captured in the analysis ( $n=8399)$ & 66.3 \\
Public hospitals (PuHs) & $n$ & 14.5 \\
Socio-medical institutions (SOMEDs) & 5567 & 1219 \\
Home care services (HCs) & 763 & 9.1 \\
Private hospitals (PrHs) & 690 & 8.2 \\
Non-profit organisations (NPOs) & 105 & 1.3 \\
Private medical offices (PrOs) & 55 & 0.7 \\
\hline
\end{tabular}


identified components were considered distinct and were not further aggregated. Other concepts or variables with substantial latent connections were aggregated to second-order constructs by averaging the specific ratings.

We compared WCS between the organisation types by predicting the 12 workplace measures according to the type of organisation using multivariate linear regression analyses with cluster-adjusted standard errors to correct for repeated measurements, controlling for workload (log distribution), duration of employment (log distribution), diploma level, sex, age and currency of the work episode. Categorical institutional effects were compared using post hoc tests with Bonferroni-adjusted significance levels.

\section{Results}

Table 4 presents the rankings of employer types based on their effects on each WCS, starting with the employer type that predicts the lowest rating in the second column and ends with the employer type that predicts the highest one (seventh column). The superscript significance labels attached to the employer types indicate differences that are statistically significant at the 5\% level. Employer types sharing a letter in their superscript significance label did not differ significantly with regard to their corresponding WCS. For example, NPOs were associated with the highest degree of perceived autonomy; however, the difference between NPOs and PrOs as well as the difference between NPOs and HCs were statistically insignificant, which is indicated through the corresponding significance labels which share a common letter, in this case, the letter ' $C$ '. The estimates and the relevant descriptive statistics may be retrieved from
Additional file 5 and visualised data may be viewed in Additional files 6 and 7.

An alternative model based on the full sample of 11 232 nurses, albeit without the incomplete control variables (sex and age), is presented in Additional files 3 and 4 . The estimates or their rankings, respectively, did not diverge heavily from those presented here. ${ }^{4}$

\section{WCS at public and private hospitals}

Nurses reported almost identical low levels of autonomy, participation and flexibility of work hours for both PuHs and PrHs compared to other types of healthcare institution, as well as significantly lower organisational commitment. Professional identification was similar at $\mathrm{PuHs}$ and PrHs to that at other institutions. Despite their common features, $\mathrm{PuH}$ and $\mathrm{PrH}$ ratings differed in several aspects. $\mathrm{PuH}$ ratings were higher for advancement opportunities, such as the opportunity to develop and use skills and for good career opportunities; these ratings were also higher compared to other types of institutions. Working at PuHs was associated with more satisfaction with salary than work at PrHs, but nurses in $\mathrm{PuHs}$ experienced greater alienation, involving, for example, work strain or aggression.

\section{WCS in non-profit organisations and home care settings} Autonomy, participation and flexibility of working hours were higher in NPOs (and, to a lesser extent, HCs) than in other types of institutions. As with PuHs, NPOs and HCs were relatively highly rated for advancement. NPOs were associated with the highest degree of organisational commitment. Job satisfaction was significantly higher at NPOs than at PuHs, PrHs and SOMEDs and higher than

Table 4 Comparison of working conditions across the different types of institutions (multivariate analysis)

\begin{tabular}{|c|c|c|c|c|c|c|}
\hline \multirow[t]{2}{*}{ Dependent variables } & \multicolumn{6}{|c|}{ Independent variables } \\
\hline & $\begin{array}{l}\text { Lowest marginal } \\
\text { prediction }\end{array}$ & & & & & $\begin{array}{l}\text { Highest marginal } \\
\text { prediction }\end{array}$ \\
\hline Autonomy & $\operatorname{PrOs}^{\mathrm{ABC}}$ & $\mathrm{PuHs}^{\mathrm{A}}$ & $\mathrm{PrHs}^{\mathrm{AB}}$ & SOMEDs ${ }^{B}$ & $\mathrm{HCs}^{\mathrm{BC}}$ & $\mathrm{NPOs}^{\mathrm{C}}$ \\
\hline Flexibility & $\mathrm{PuHs}^{\mathrm{A}}$ & SOMEDs ${ }^{A}$ & $\mathrm{PrHs}^{\mathrm{AB}}$ & $\mathrm{PrOs}^{\mathrm{AB}}$ & $\mathrm{HCs}^{\mathrm{B}}$ & $\mathrm{NPOs}^{\mathrm{B}}$ \\
\hline Participation & $\mathrm{PuHs}^{\mathrm{A}}$ & $\mathrm{PrHs}^{\mathrm{A}}$ & $\mathrm{PrOs}^{\mathrm{ABC}}$ & SOMEDs ${ }^{B}$ & $\mathrm{HCs}^{\mathrm{C}}$ & $\mathrm{NPOs}^{\mathrm{BC}}$ \\
\hline Relationships & SOMEDs ${ }^{A}$ & $\mathrm{PrHs}^{\mathrm{B}}$ & $\mathrm{PuHs} s^{\mathrm{B}}$ & $\mathrm{NPOs}^{\mathrm{AB}}$ & $\mathrm{HCs}^{\mathrm{B}}$ & $\mathrm{PrOs}^{\mathrm{B}}$ \\
\hline Recognition & SOMEDs ${ }^{\mathrm{A}}$ & $\mathrm{PrHs} s^{\mathrm{AB}}$ & $\mathrm{PuHs} \mathrm{s}^{\mathrm{AB}}$ & $\mathrm{HCs}^{\mathrm{C}}$ & $\mathrm{NPOs}^{\mathrm{BC}}$ & $\mathrm{PrOs}^{\mathrm{BC}}$ \\
\hline Absence of alienation & SOMEDS & $\mathrm{PuHs}^{\mathrm{C}}$ & $\mathrm{PrHs}^{\mathrm{B}}$ & $\mathrm{HCS}^{\mathrm{AB}}$ & $N P O s^{A B C}$ & $\mathrm{PrOs}^{\mathrm{A}}$ \\
\hline Advancement & $\operatorname{PrOs}^{\mathrm{A}}$ & SOMEDs ${ }^{A}$ & $\mathrm{PrHs}^{\mathrm{AB}}$ & $\mathrm{HCs}^{\mathrm{C}}$ & $N P O s^{B C}$ & $\mathrm{PuHs} \mathrm{s}^{\mathrm{C}}$ \\
\hline Organisational commitment & $\mathrm{PrHs}^{\mathrm{A}}$ & $\mathrm{PuHs} s^{\mathrm{A}}$ & SOMEDs ${ }^{\mathrm{AB}}$ & $\mathrm{HCs}^{\mathrm{B}}$ & $\operatorname{PrOs}^{\mathrm{ABC}}$ & $\mathrm{NPOs}^{\mathrm{C}}$ \\
\hline Professional identification & $\operatorname{PrOs}^{\mathrm{A}}$ & $\mathrm{NPOS}^{\mathrm{A}}$ & $\mathrm{HCs}^{\mathrm{A}}$ & $\mathrm{PuHs} \mathrm{s}^{\mathrm{A}}$ & $\mathrm{PrHs}^{\mathrm{A}}$ & $\mathrm{PrHs}^{\mathrm{A}}$ \\
\hline Satisfaction with salary & $\mathrm{PrHs}^{\mathrm{A}}$ & SOMEDs $^{\mathrm{B}}$ & $\mathrm{PuHs}^{\mathrm{B}}$ & $\mathrm{HCs}^{\mathrm{B}}$ & $\mathrm{PrOs}^{\mathrm{AB}}$ & $N P O s^{B}$ \\
\hline Job satisfaction & SOMEDs ${ }^{\mathrm{A}}$ & $\mathrm{PrHs} s^{\mathrm{AB}}$ & $\mathrm{PuHs}^{\mathrm{B}}$ & $\mathrm{HCs}^{\mathrm{B}}$ & $\operatorname{PrOs}^{\mathrm{ABC}}$ & $\mathrm{NPOs}^{\mathrm{c}}$ \\
\hline No turnover intention* & $\mathrm{PrHs}^{\mathrm{B}}$ & $\mathrm{NPOs}{ }^{\mathrm{AB}}$ & SOMEDs ${ }^{\mathrm{AB}}$ & $\mathrm{PuHs} \mathrm{s}^{\mathrm{AB}}$ & $\mathrm{HCs}^{\mathrm{A}}$ & $\mathrm{PrOs}^{\mathrm{AB}}$ \\
\hline
\end{tabular}

Notes: Cluster-robust multivariate linear regressions. Variables included in the model, but not shown, are sex, age, diploma, currency of the work episode, workload (In) and duration (In) of employment. Superscript significance labels: employer types sharing a letter in the label did not differ significantly at the 5-percent level with regard to their corresponding WCS. *Only assessed for the current work episode 
at HCs. NPOs and HCs were average for alienation and for relationships with superiors and colleagues.

\section{WCS at socio-medical institutions}

SOMED work was considered to be significantly more alienating than work at other institutions, i.e. more stressful, exhausting and with greater interference from non-nursing tasks and aggression. SOMED nurses were more likely to report staff shortages and poor quality of care, as well as rather low aspects of relationships, with a difficult work atmosphere and a less supportive environment and rather low levels of perceived recognition. Conversely, SOMED workplaces were rated higher than $\mathrm{PuHs}$ and PrHs for autonomy and participation.

\section{WCS at private medical offices}

PrOs were rated higher than the other institutions for some aspects of relationships and were associated with significantly less alienation. They were also associated with higher care quality than the other types of institutions except for NPOs and with less aggressive behaviour. ${ }^{5}$ However, PrO workplaces were less frequently perceived to offer good advancement opportunities and nurses at PrOs identified with their profession significantly less than at almost all the other institutions (significant at the $10 \%$ level).

\section{Discussion}

Overall, the findings supported the Regulation hypothesis, according to which nurses perceive less autonomy and participation in the larger types of healthcare institutions. In hospitals, nurses had less autonomy and were less likely to participate in important decisions and, especially in PuHs, nurses perceived a higher degree of alienation compared to other institutions.

There was no obvious support for the Resource hypothesis, according to which larger types of organisations offer greater extrinsic rewards and advancement opportunities. Although PuHs, as large institutions, offered greater advancement opportunities than smaller types of institutions, but this was not the case for PrHs, which are also large institutions. Furthermore, the differences in satisfaction with salary did not indicate better salaries at larger institutions.

The analysis did not support the Pricing-system hypothesis, according to which nurses perceive greater alienation because of economic pressure induced through flat-rate priced treatments (Diagnosis-Related Groups) at hospitals. At the level of first-order variables, PuH workplaces were rated higher than other healthcare institutions in terms of work strain (mostly without statistical significance) and were lower for perceived care quality. Alienation (a second-order construct) was more prevalent at PuHs than at most other institution types. However, PrHs, which also price at flat rates per case, were rated as average for these variables; thus, the higher alienation at PuHs may not result from the pricing system.

The Long-term care hypothesis was supported by the findings. SOMED workplaces, often concerned with additional stressors, were associated with alienation.

$\mathrm{HC}$ workplaces were associated with greater participation and recognition and a tendency for better relationships than other workplaces (see Additional files 6 and 7). Similarly, $\mathrm{PrO}$ workplaces were above average for recognition and relationships. These findings supported the Outpatient hypothesis.

There was support for the For-profit, Non-profit and Public hypotheses. PrHs were perceived as less alienating than PuHs, providing support for the For-profit hypothesis, that is, nurses perceive more convenient WCS, such as less stress and aggression, when there is specific selection of treatments. However, relationships were equally rated in PrHs and PuHs. Supporting the Non-profit hypothesis, NPOs were rated highest for intrinsic aspects and for nurses' organisational commitment. The Public hypothesis was also supported by career opportunities being especially associated with PuHs.

Although these findings refer to the Swiss healthcare sector, they may also be relevant to other countries with similar economic and political contexts, as well to low- and middle-income countries. Although nursing conditions may vary between countries according to their specific health systems, it might be expected that the mechanisms for within-country variance related to the organisational characteristics of healthcare providers, such as size, field of activity and ownership, would be similar between countries. However, the degree to which healthcare organisations may adjust or compensate for WCS associated with inherent organisational characteristics may be highly dependent on country-specific political and economic contexts, such as the level of competitiveness in the health sector, as well as the degree to which nurses may react to certain WCS, which may depend on the state of the labour market, employee mobility and cultural background.

This study had some limitations. Since a sampling frame such as an eligible registry of professional nurses did not exist, the surveyed sample may lack representativeness due to self-selection bias. Moreover, the crosssectional analyses of working conditions did not reveal causal directions and did not address fixed individualspecific effects potentially correlated with the independent variables.

The data of the original study were self-reported and, thus, possibly affected by response and social desirability biases [65]. The retrospective survey design potentially introduced data bias through memory loss about older 
job episodes and missing values due to the length of the questionnaire [8]. In addition, a programming error in the questionnaire in the first few months of the survey resulted in data about sex and age only being available for less than half of the sample, limiting the sample size used in the regression models that included sex and age as control variables. Finally, our study was limited to the variables available in the original study. Although a broad range of WCS were assessed, we cannot claim to have assessed the full range of relevant WCS, including, for example, the attractiveness or interest of the tasks themselves. Furthermore, we could not perform multilevel analyses that clustered specific institutions because they were not identified in the original study. The final limitation of this study was its restricted immediacy in testing the hypotheses because the theorised effects of size, activity type and ownership were only measured through interactions with other factors associated with these categories.

\section{Conclusions}

The focus of this study on workplace differences between types of healthcare organisations rather than on characteristics of the healthcare sector as a whole showed that WCS in nursing, although generally challenging, differed between institution types. WCS varied according to the type of patient and treatment, institution size and organisational ownership. Although the nature of some institutions predisposes them to specific characteristics, healthcare employers should strive to eliminate their institution type-specific WCS deficits to remain competitive on the labour market, while exploiting their inherent strengths to create unique institutional branding to help the recruitment and retention of nurses. PrHs and PuHs need to improve autonomy and participation in the workplace, PrOs should offer more training and advancement opportunities and SOMEDs should try to compensate for their demanding work environment by offering better formal WCS. PuHs can communicate their advantage in terms of advancement opportunities, PrHs and PrOs may attract applicants with a more convenient work environment and NPOs and HCs may succeed in recruitment by promoting their high ratings for self-determined work and recognition.

\section{Endnotes}

${ }^{1}$ See Additional file 8 for more details on the categorisation.

${ }^{2}$ Standardisation was not applied due to the longitudinal nature of the data [66] and easiness of results reception. Values were transformed as New value $=$ Old value $\times(3 / 4)+(1 / 4)$.

${ }^{3}$ For a detailed overview of the constructs and items, see Additional file 9.
${ }^{4}$ The effects remained relatively stable across the sample and the subsample (with the control variables sex and age). This implied that the differences were robust against sex and age differences and that the sample proportions and associated representation of the population were unaffected by including only the cases with complete information.

${ }^{5}$ See Additional file 6 for comparisons of the firstorder constructs.

\section{Additional files}

Additional file 1: Theoretical arguments for institution-dependent variance in working conditions. (DOCX $33 \mathrm{~kb}$ )

Additional file 2: Description of the extended study sample. (DOCX $13 \mathrm{~kb}$ )

Additional file 3: Compared working conditions (model without age and sex as control variables). (DOCX $15 \mathrm{~kb}$ )

Additional file 4: Compared working conditions (visualised; model without age and sex as control variables). (DOCX $124 \mathrm{~kb}$ )

Additional file 5: Descriptive statistics and institutional effects (fully adjusted models). (DOCX $15 \mathrm{~kb}$ )

Additional file 6: Compared working conditions on the level of first-order constructs. (DOCX $122 \mathrm{~kb}$ )

Additional file 7: Compared working conditions (visualised). (DOCX 126 kb)

Additional file 8: Categories of medical institutions. (DOCX $14 \mathrm{~kb}$ ) Additional file 9: Measures of working conditions. (DOCX 17 kb)

\section{Abbreviations}

HCs: Home care services; NPOs: Non-profit organisations; PrHs: Private for-profit hospitals; PrOs: Private medical offices; PuHs: Public hospitals; SOMEDs: Socio-medical institutions; WCS: Working conditions

\section{Acknowledgements}

We thank the Nurses at Work team members: Véronique Addor [University of Applied Sciences and Arts Western Switzerland, (HES-SO), Principal Investigator] Jacques-Antoine Gauthier (University of Lausanne), René Schwendimann (University of Basel), Adeline Paignon [University of Applied Sciences and Arts Western Switzerland (HES-SO)], Dalit Jäckel (University of Basel) and Boris Wernli [Swiss Centre of Expertise in the Social Sciences (FORS)].

\section{Funding}

The Nurses at Work study was supported by the Swiss National Science Foundation Swiss National Science Foundation grant \#105318_147159, the Swiss Health Observatory grant \#150010772, the State Secretariat for Education, Research and Innovation grant \#88.2013.0042, the Federal Office of Public Health grant \#1014-50109, and the Haute école spécialisée de Suisse occidentale (HES-SO).

Availability of data and materials

The Nurses at Work database was made available by the authors upon submission of a research protocol.

\section{Authors' contributions}

RA performed the statistical analyses, interpreted the data, and is the main contributor to the manuscript. VA was the Principal Investigator of the Nurses at Work study, responsible for the study design, the questionnaire development and the data collection; she contributed to the manuscript. Both authors read and approved the final manuscript.

Ethics approval and consent to participate

Since the nurses at work online suvey pertains to health professionals with no inclusion of other 'human subjects' [Switzerland's Law on Research on 
Human Beings (L 810.30, art. 118)], this sub-study required no approval by the Swiss Ethics Commission. However, the Nurses at Work study requested and obtained a favourable presidential opinion from the Swiss Ethics Committee on research involving humans (Protocol 119/14 of April 16, 2014)

\section{Consent for publication}

Not applicable

\section{Competing interests}

The authors declare that they have no competing interests.

\section{Publisher's Note}

Springer Nature remains neutral with regard to jurisdictional claims in published maps and institutional affiliations.

\section{Author details}

${ }^{1}$ University of Fribourg (CH), Bd de Pérolles 90, CH-1700 Freiburg, Switzerland. ${ }^{2}$ University of Applied Sciences and Arts Western Switzerland (HES-SO), Geneva, Switzerland.

Received: 13 June 2018 Accepted: 15 October 2018 Published online: 09 November 2018

\section{References}

1. Marć M, Bartosiewicz A, Burzyńska J, Chmiel Z, Januszewicz P. A nursing shortage-a prospect of global and local policies. Int Nurs Rev. 2018. https:// onlinelibrary.wiley.com/doi/epdf/10.1111/inr.12473. Accessed 30 Oct 2018.

2. Fox RL, Abrahamson K. A critical examination of the U.S. nursing shortage: contributing factors, public policy implications. Nurs Forum. 2009:44(4):235-44.

3. Addor V, Jeannin A, Schwendimann R, Roulet Jeanneret F. Career paths of 1988 and 1998 nurse graduates in Switzerland: nurses at work pilot study. J Nurs Manag. 2017;25(4):318-25

4. Nei D, Snyder LA, Litwiller BJ. Promoting retention of nurses: a meta-analytic examination of causes of nurse turnover. Health Care Manag Rev. 2015; 40(3):237-53.

5. Currie EJ, Hill RAC. What are the reasons for high turnover in nursing? A discussion of presumed causal factors and remedies. Int J Nurs Stud. 2012; 49(9):1180-9.

6. Poghosyan L, Liu J, Shang J, D'aunno T. Practice environments and job satisfaction and turnover intentions of nurse practitioners: implications for primary care workforce capacity. Health Care Manag Rev. 2017;42(2):162-71.

7. Al-Hamdan Z, Manojlovich M, Tanima B. Jordanian nursing work environments, intent to stay, and job satisfaction. J Nurs Scholarsh. 2017 49(1):103-10.

8. De Pietro C, Camenzind P, Sturny I, Crivelli L, Edwards-Garavoglia S, Spranger A, et al. Switzerland: health system review. Health Syst Transit. 2015:17(4):1-288.

9. Shamian J, Kerr MS, Laschinger HKS, Thomson D. A hospital-level analysis of the work environment and workforce health indicators for registered nurses in Ontario's acute-care hospitals. Can J Nurs Res Arch. 2016;33(4):35-50.

10. Chamberlain SA, Gruneir A, Hoben M, Squires JE, Cummings GG, Estabrooks CA. Influence of organizational context on nursing home staff burnout: a cross-sectional survey of care aides in Western Canada. Int J Nurs Stud. 2017;71:60-9.

11. Stordeur S, D'hoore W, van der Heijden B, Dibisceglie M, Laine M, van der Schoot E. Leadership, job satisfaction and nurses' commitment. In: Hasselhorn H-M, Tackenberg P, Müller BH, editors. Working conditions and intent to leave the profession among nursing staff in Europe. Stockholm: National Institute for Working Life; 2003. p. 28-45.

12. Cocco E, Gatti M, de Mendonça Lima CA, Camus V. A comparative study of stress and burnout among staff caregivers in nursing homes and acute geriatric wards. Int J Geriatr Psychiatry. 2003;18(1):78-85.

13. van der Schoot E, Ogińska H, Estryn-Behar M. Burnout in the nursing profession in Europe. In: Hasselhorn H-M, Tackenberg P, Müller BH, editors. Working conditions and intent to leave the profession among nursing staff in Europe. Stockholm: National Institute for Working Life; 2003. p. 53-7.

14. McHugh MD, Kutney-Lee A, Cimiotti JP, Sloane DM, Aiken LH. Nurses' widespread job dissatisfaction, burnout, and frustration with health benefits signal problems for patient care. Health Aff. 2011;30(2):202-10.
15. Braun B, Klinke S, Müller R, Rosenbrock R. Einfluss der DRGs auf Arbeitsbedingungen und Versorgungsqualität von Pflegekräften im Krankenhaus: Ergebnisse einer bundesweiten schriftlichen Befragung repräsentativer Stichproben von Pflegekräften an Akutkrankenhäusern in den Jahren 2003, 2006 und 2008. 2011. http://nbn-resolving.de/urn:nbn:de: 0168-ssoar-375444.

16. Hegney D, Plank A, Parker V. Extrinsic and intrinsic work values: their impact on job satisfaction in nursing. J Nurs Manag. 2006;14(4):271-81.

17. Pokorski J, van der Schoot E, Wickström G, Pokorska J, Hasselhorn H-M (2003). Meaning of work in the European nursing profession. In: Hasselhorn H-M, Tackenberg P, Müller BH, editors. Working conditions and intent to leave the profession among nursing staff in Europe. Stockholm: National Institute for Working Life; 2003. p. 58-63.

18. Laine $M$, Pentti J, Wickström G. Intent to leave nursing in Finland. In: Hasselhorn H-M, Tackenberg P, Müller BH, editors. Working conditions and intent to leave the profession among nursing staff in Europe. Stockholm: National Institute for Working Life; 2003. p. 146-56.

19. Stordeur S, Kiss P, Verpraet R, De Meester M, Braeckman L, D'hoore W. Intent to leave nursing in Belgium. In: Hasselhorn H-M, Tackenberg P, Müller $\mathrm{BH}$, editors. Working conditions and intent to leave the profession among nursing staff in Europe. Stockholm: National Institute for Working Life; 2003. p. $125-35$.

20. van der Schoot $E$, van der Heijden B. Intent to leave nursing in the Netherlands. In: Hasselhorn H-M, Tackenberg P, Müller BH, editors. Working conditions and intent to leave the profession among nursing staff in Europe. Stockholm: National Institute for Working Life; 2003. p. 193-202.

21. Sellgren SF, Kajermo KN, Ekvall G, Tomson G. Nursing staff turnover at a Swedish university hospital: an exploratory study. J Clin Nurs. 2009;18(22): $3181-9$

22. Han K, Trinkoff AM, Gurses AP. Work-related factors, job satisfaction and intent to leave the current job among United States nurses. J Clin Nurs. 2015;24(21-22):3224-32.

23. Hasson $\mathrm{H}$, Arnetz JE. Nursing staff competence, work strain, stress and satisfaction in elderly care: a comparison of home-based care and nursing homes. J Clin Nurs. 2008:17(4):468-81.

24. Lambrechts G, Kuppens S, Maes B. Staff variables associated with the challenging behaviour of clients with severe or profound intellectual disabilities. J Intellect Disabil Res. 2009;53(7):620-32.

25. Chung MC, Harding C. Investigating burnout and psychological well-being of staff working with people with intellectual disabilities and challenging behaviour: the role of personality. J Appl Res Intellect Disabil. 2009;22(6): 549-60.

26. Josephson M, Lindberg P, Voss M, Alfredsson L, Vingård E. The same factors influence job turnover and long spells of sick leave-a 3-year follow-up of Swedish nurses. Eur J Public Health. 2008;18(4):380-5.

27. Gould D, Fontenla M, Anderson S, Conway L, Hinds K. Intention to leave nursing in the United Kingdom. In: Hasselhorn H-M, Tackenberg P, Müller $\mathrm{BH}$, editors. Working conditions and intent to leave the profession among nursing staff in Europe. Stockholm: National Institute for Working Life; 2003. p. 171-81.

28. Virtanen $\mathrm{P}$, Oksanen T, Kivimäki M, Virtanen M, Pentti J, Vahtera J. Work stress and health in primary health care physicians and hospital physicians. Occup Environ Med. 2008;65(5):364-6.

29. Stacey CL. Finding dignity in dirty work: the constraints and rewards of lowwage home care labour. Sociol Health IIIn. 2005;27(6):831-54.

30. Choi J, Miller P. Registered nurse perception of patient assignment linking to working conditions and outcomes. J Nurs Scholarsh. 2018;50(5):530-39.

31. Choi J, Boyle DK. Differences in nursing practice environment among US acute care unit types: a descriptive study. Int J Nurs Stud. 2014;51(11):1441-9.

32. Brunetto $Y$, Farr-Wharton $R$, Shacklock K. The impact of supervisorsubordinate relationships on morale: implications for public and private sector nurses' commitment. Hum Resour Manag J. 2010; 20(2):206-25

33. Wei CY, Chiou ST, Chien LY, Huang N. Workplace violence against nurses-prevalence and association with hospital organizational characteristics and health-promotion efforts: cross-sectional study. Int J Nurs Stud. 2016:56:63-70.

34. Rojas D, Seghieri C, Nuti S. Organizational climate: comparing private and public hospitals within professional roles. Suma De Negocios. 2014;5(11):10-4. 
35. Tyson PD, Pongruengphant R. Five-year follow-up study of stress among nurses in public and private hospitals in Thailand. Int J Nurs Stud. 2004; 41(3):247-54.

36. Peters DH, Chakraborty S, Mahapatra P, Steinhardt L. Job satisfaction and motivation of health workers in public and private sectors: cross-sectional analysis from two Indian states. Hum Resour Health. 2010;8(1):27.

37. Coetzee SK, Klopper HC, Ellis SM, Aiken LH. A tale of two systems-nurses practice environment, well being, perceived quality of care and patient safety in private and public hospitals in South Africa: a questionnaire survey. Int J Nurs Stud. 2013;50(2):162-73.

38. Mrayyan MT. Nurse job satisfaction and retention: comparing public to private hospitals in Jordan. J Nurs Manag. 2005;13(1):40-50.

39. AbuAIRub RF, Omari FH, Al-Zaru IM. Support, satisfaction and retention among Jordanian nurses in private and public hospitals. Int Nurs Rev. 2009; 56(3):326-32

40. Basu S, Andrews J, Kishore S, Panjabi R, Stuckler D. Comparative performance of private and public healthcare systems in low-and middleincome countries: a systematic review. PLoS Med. 2012;9(6):e1001244.

41. Hsu AT, Berta W, Coyte PC, Laporte A. Staffing in Ontario's long-term care homes: differences by profit status and chain ownership. Can J Aging. 2016; 35(2):175-89.

42. Hansen N, Sverke M, Näswall K. Predicting nurse burnout from demands and resources in three acute care hospitals under different forms of ownership: a cross-sectional questionnaire survey. Int J Nurs Stud. 2009; 46(1):95-106.

43. Ben-Ner A, Ren T, Paulson DF. A sectoral comparison of wage levels and wage inequality in human services industries. Nonprofit Volunt Sect $Q$ 2010;40(4):608-33.

44. Hillmer MP, Wodchis WP, Gill SS, Anderson GM, Rochon PA. Nursing home profit status and quality of care: is there any evidence of an association? Med Care Res Rev. 2005;62(2):139-66

45. Chesteen S, Helgheim B, Randall T, Wardell D. Comparing quality of care in non-profit and for-profit nursing homes: a process perspective. J Oper Manag. 2005;23(2):229-42.

46. Harrington C, Woolhandler S, Mullan J, Carrillo H, Himmelstein DU. Does investor ownership of nursing homes compromise the quality of care? Am J Public Health. 2001;91(9):1452-5.

47. Borzaga C, Tortia E. Worker motivations, job satisfaction, and loyalty in public and nonprofit social services. Nonprofit Volunt Sect Q. 2006;35(2): 225-48.

48. Benz M. Not for the profit, but for the satisfaction? - evidence on worker well-being in non-profit firms. Kyklos. 2005;58(2):155-76.

49. Lin PY, MacLennan S, Hunt N, Cox T. The influences of nursing transformational leadership style on the quality of nurses' working lives in Taiwan: a cross-sectional quantitative study. BMC Nurs. 2015;14(1):33.

50. Pugh D, Hickson D, Hinings $C$. An empirical taxonomy of structures of work organizations. Adm Sci Q. 1969;14(1):115-26.

51. Härenstam A, Marklund S, Berntson E, Bolin M, Ylander J. Understanding the organisational impact on working conditions and health. Stockholm: National Institute for Working Life; 2006

52. Addor $V$, Schwendimann $R$, Gauthier J-A, Wernli B, Jäckel D, Paignon A. «nurses at work» - Studie zu den Laufbahnen im Pflegeberuf über die letzten 40 Jahre in der Schweiz (Obsan Bulletin 8/2016). Schweizerisches Gesundheitsobservatorium: Neuchâtel; 2016

53. Spreitzer GM. Psychological empowerment in the workplace: dimensions, measurement, and validation. Acad Manag J. 1995;38(5):1442-65.

54. Lake ET. Development of the practice environment scale of the nursing work index. Res Nurs Health. 2002;25(3):176-88.

55. Karasek R, Brisson C, Kawakami N, Houtman I, Bongers P, Amick B. The job content questionnaire (JCQ): an instrument for internationally comparative assessments of psychosocial job characteristics. J Occup Health Psychol. 1998;3(4):322-55.

56. Einarsen S, Raknes Bl. Harassment in the workplace and the victimization of men. Violence Vict. 1997;12(3):247-63.

57. Pejtersen JH, Kristensen TS, Borg V, Bjorner JB. The second version of the Copenhagen psychosocial questionnaire. Scand J Public Health. 2010;38(3_ suppl):8-24.

58. Dupret É, Bocéréan C, Teherani M, Feltrin M. Le COPSOQ: un nouveau questionnaire français d'évaluation des risques psychosociaux. Santé publique. 2012;24(3):189-207.
59. Bonneterre V, Jolivet A, Lang T, Caroly S, Ehlinger V, Sobaszek A, de Gaudemaris R. Évaluation des contraintes psychologiques et organisationnelles (CPO) chez les soignants: cohorte ORSOSA et applications. Arch Mal Prof Environ. 2010;71(3):489-92.

60. Ryden MB, Bossenmaier M, McLachlan C. Agressive behavior in cognitively impaired nursing home residents. Res Nurs Health. 1991;14(2):87-95.

61. Maslach C, Jackson SE, Leiter MPMBI. Maslach burnout inventory. CPP, Incorporated; 1996.

62. Spector PE. Measurement of human service staff satisfaction: development of the job satisfaction survey. Am J Community Psychol. 1985;13(6):693-713.

63. Allen NJ, Meyer JP. The measurement and antecedents of affective, continuance and normative commitment to the organization. J Occup Organ Psychol. 1990;63(1):1-18.

64. Miller HE, Katerberg R, Hulin CL. Evaluation of the Mobley, Horner, and Hollingsworth model of employee turnover. J Appl Psychol. 1979; 64(5):509-17

65. Demetriou C, Ozer BU, Essau CA. Self-report questionnaires. In: Cautin RL, Lilienfeld SO, editors. The encyclopedia of clinical psychology; 2015. p. 1-6.

66. Moeller J. A word on standardization in longitudinal studies: don't. Front Psychol. 2015;6:1389.

67. Blau PM. A formal theory of differentiation in organizations. Am Sociol Rev. 1970;35(2):201-18

68. Astley WG. Organizational size and bureaucratic structure. Organ Stud. 1985; 6(3):201-28

69. Appelbaum E, Berg P. High-performance work systems and labor market structures. In: Berg I, Kalleberg AL, editors. Sourcebook of labor markets. USA: Springer; 2001. p. 271-93.

70. Ryan RM, Deci EL. Self-determination theory and the facilitation of intrinsic motivation, social development, and well-being. Am Psychol. 2000;55:68-78.

71. Kalleberg A, Van Buren M. Is bigger better? Explaining the relationship between organization size and job rewards. Am Sociol Rev. 1996;61(1):47-66.

72. MacDermid S, Williams M, Marks S, Heilbrun G. Is small beautiful? Workfamily tension, work conditions, and organizational size. Fam Relat. 1994; 43(2):159-67.

73. Hackman JR, Oldham G. Work Redesign. MA: Addison-Wesley; 1980.

74. Downie M, Mageau GA, Koestner R. What makes for a pleasant social interaction? Motivational dynamics of interpersonal relations. J Soc Psychol. 2008;148(5):523-34.

75. Côté S. A social interaction model of the effects of emotion regulation on work strain. Acad Manag Rev. 2005;30(3):509-30.

76. Brindle D. Nursing shortages are worst in care homes and agency workers fill the gap. In: The Guardian; 2015. https://www.theguardian.com/society/ 2015/jun/03/nursing-shortages-worst-care-homes-agency-workers-fill-gap.

77. Hegney D, McCarthy A, Rogers-Clark C, Gorman D. Why nurses are attracted to rural and remote practice. Aust J Rural Health. 2002;10(3):178-86.

78. Weisbrod BA. Toward a theory of the voluntary non-profit sector in a three sector economy. In: Phelps E, editor. Altruism, morality and economic theory. New York: Russell Sage; 1975. p. 171-96.

79. Perry JL. Bringing society in: toward a theory of public-service motivation. J Public Adm Res Theory. 2000;10(2):471-88.

80. Bayindir EE. Hospital ownership type and treatment choices. J Health Econ. 2012;31(2):359-70.

81. Horwitz JR. Making profits and providing care: comparing nonprofit, forprofit, and government hospitals. Health Aff. 2015;24(3):790-801.

82. Mirvis PH, Hackett EJ. Work and work force characteristics in the nonprofit sector. Mon Labor Rev. 1983:106(4):3-12.

83. Chen H-F, Bazzoli GJ, Hsieh H-M. Hospital financial conditions and the provision of unprofitable services. Atl Econ J. 2009:37(3):259-77. 